\title{
Validation of the hdm models forcrack initiation and development, rutting and roughness of the pavement
}

\author{
Slobodan Ognjenović ${ }^{1}$, Ivona Nedevska, ${ }^{1, *}$ and AndreyPustovgar ${ }^{2}$ \\ ${ }^{1}$ Ss. Cyril and Methodius University of Skopje, Goce Delcev 9, 1000 Skopje, Macedonia \\ ${ }^{2}$ Moscow State University of Civil Engineering, Yaroslavskoeshosse, 26, Moscow, 129337, Russia
}

\begin{abstract}
Worldwide practice recommends validation of the HDM models with some other software that can be used for comparison of the forecasting results. The program package MATLAB is used in this case, as it enables for modelling of all the HDM models. A statistic validation of the results of the forecasts concerning the condition of the pavements in HDM with the on-field measuring results was also performed. This paper shall present the results of the validation of the coefficients of calibration of the deterioration models in HDM 4 on the Macedonian highways.
\end{abstract}

\section{Introduction}

The research of the Macedonian highways with the purpose of establishing of the coefficients and calibrating the deterioration models in HDM was performed in the period of 2010 to 2014. The data on the roughness and those related to the initiation and development of rutting, measured in the period of 2002 to 2006 were also used in the research.

The research results are presented on the following table:

Table 1.Review of the calibration coefficients of the Macedonian highways.

\begin{tabular}{|c|c|c|}
\hline Calibraiton coefficient & Damage & Value \\
\hline $\mathrm{K}_{\mathrm{cia}}$ & Crack initiation & 0.59 \\
\hline $\mathrm{K}_{\mathrm{cpa}}$ & Cracks development & 1.49 \\
\hline $\mathrm{K}_{\mathrm{rid}}$ & Initial densification (rutting) & 1.0 \\
\hline $\mathrm{K}_{\mathrm{rst}}$ & Structural deformation (rutting) & 1.0 \\
\hline $\mathrm{K}_{\mathrm{rpd}}$ & Plastic deformation (rutting) & 1.0 \\
\hline $\mathrm{K}_{\mathrm{rsw}}$ & Use of winter tyres (rutting) & 1.0 \\
\hline $\mathrm{K}_{\mathrm{pd}}$ & Rutting & 0.62 \\
\hline
\end{tabular}

\footnotetext{
*Corresponding author: ivona nedevska@live.com
} 


\begin{tabular}{|c|c|c|}
\hline $\mathrm{K}_{\mathrm{vi}}$ & Ravelling & 1.0 \\
\hline $\mathrm{K}_{\mathrm{gp}}$ & Roughness & 0.91 \\
\hline $\mathrm{K}_{\mathrm{gm}}$ & Environment (roughness) & 1.0 \\
\hline $\mathrm{K}_{\mathrm{snpk}}$ & Reduction of SNP & 1.0 \\
\hline $\mathrm{K}_{\mathrm{pi}}$ & Potholes initiation & 1.0 \\
\hline $\mathrm{K}_{\mathrm{pp}}$ & Development of potholes & 1.0 \\
\hline $\mathrm{K}_{\mathrm{eb}}$ & Damages along the edge break of the pavement & 1.0 \\
\hline $\mathrm{K}_{\mathrm{td}}$ & Texture depth & 1.0 \\
\hline $\mathrm{K}_{\mathrm{sfc}}$ & Skid resistance & 1.0 \\
\hline
\end{tabular}

It must be mentioned that the values in the table, which are different from 1 refer to the calibraiton coefficients obtained in the research. The coefficients with the value of 1 (default value in HDM) refer to the models that are not included in the research due to lack of data.

\section{Validation of the HDM models in MATLAB}

Due to the difference in software and the limitations imposed in conformity thereto, there are certain differences in the modeling of cracks. In HDM the crack initiation is an exact value of time until the initiation of the first crack in decimal values of the crack percentages, whereas in MATLAB, due to the software limitations, the value of the crack percentage is a whole number. In such case, due to the small values of the crack percentages until the initiation of the first crack $(0.5 \%$ of the surface of a traffic lane) the small differences in value give larger percentage differences between the two softwares. This difference if further reflected on the crack development and therefore the percentage differences in the crack development models are considerably high.

As for the models of roughness and initiation and development of rutting the values obtained by several consecutive measures are low and the percentage differences are considerably lower in comparison of the crack development model.

As a result, the forecasts in MATLAB give acceptable, but not identical forecasts concerning the condition of development of cracks, rutting and roughness in relation to the HDM.

The analyses were performed with the same input data in both softwares. Table2. gives a review of the percentage difference between the results obtained by HDM and those obtained by MATLAB.

Table2.Percentage difference in the models of development of cracks, rutting and roughness in HDMandMATLAB.

\begin{tabular}{|c|c|c|c|c|l|c|c|c|}
\hline \multicolumn{2}{|c|}{ Development of cracks } & \multicolumn{3}{|c|}{ Rutting } & \multicolumn{3}{c|}{ Roughness } \\
\hline $\begin{array}{c}\text { Max. } \\
\text { difference }\end{array}$ & $\begin{array}{c}\text { Average } \\
\text { difference }\end{array}$ & $\mathrm{R}^{2}$ & $\begin{array}{c}\text { Max. } \\
\text { difference }\end{array}$ & $\begin{array}{c}\text { Average } \\
\text { difference }\end{array}$ & $\mathrm{R}^{2}$ & $\begin{array}{c}\text { Max. } \\
\text { difference }\end{array}$ & $\begin{array}{c}\text { Average } \\
\text { difference }\end{array}$ & $\mathrm{R}^{2}$ \\
\hline $56 \%$ & $9 \%$ & 0.99 & $1 \%$ & $0 \%$ & 1.0 & $5 \%$ & $1 \%$ & 1.0 \\
\hline
\end{tabular}

Pictures1, 2 and 3 graphically represent the comparison of the results of all the three models. 


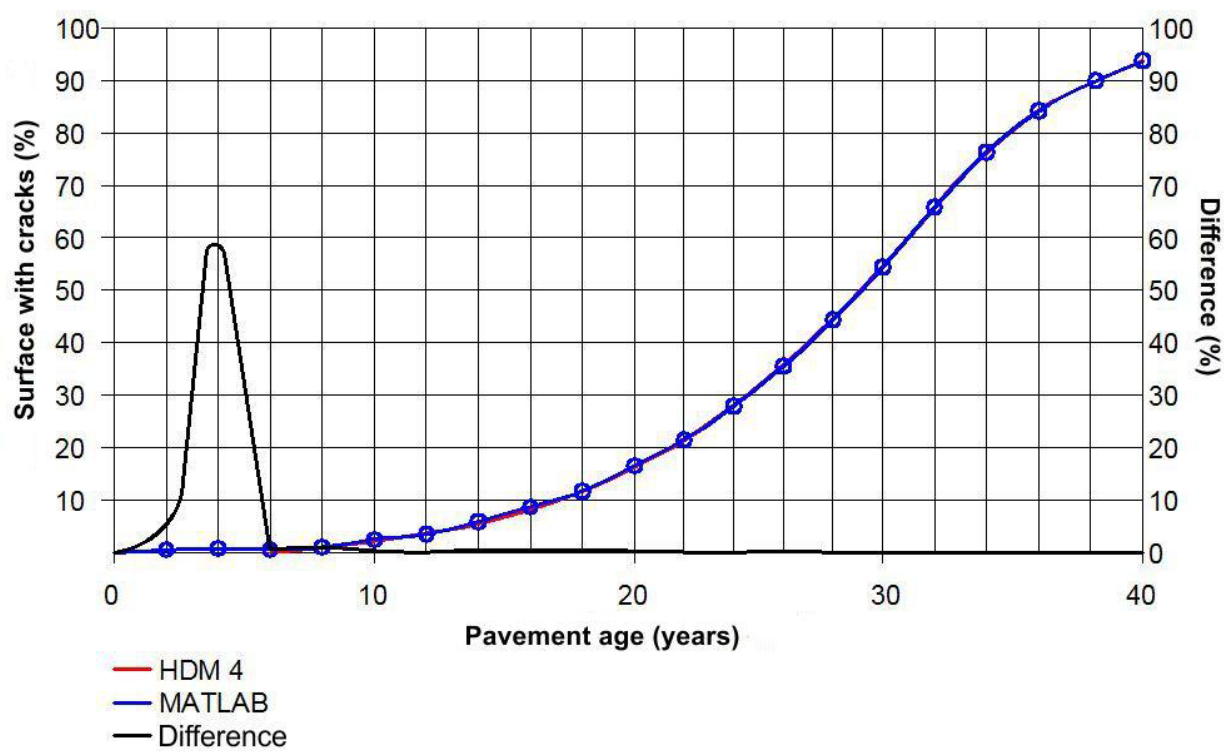

Fig. 1.Validation of the crack developing model in MATLAB.

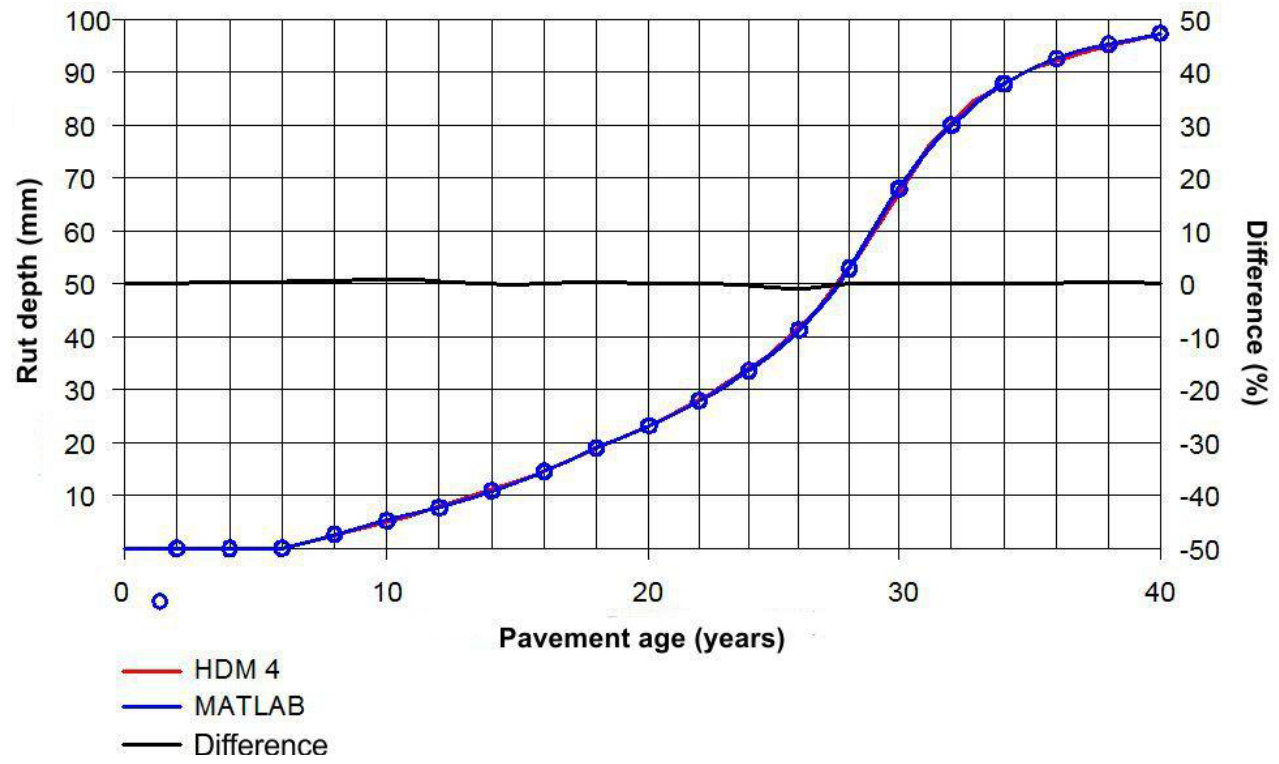

Fig. 2.Validation of the rutting model in MATLAB. 


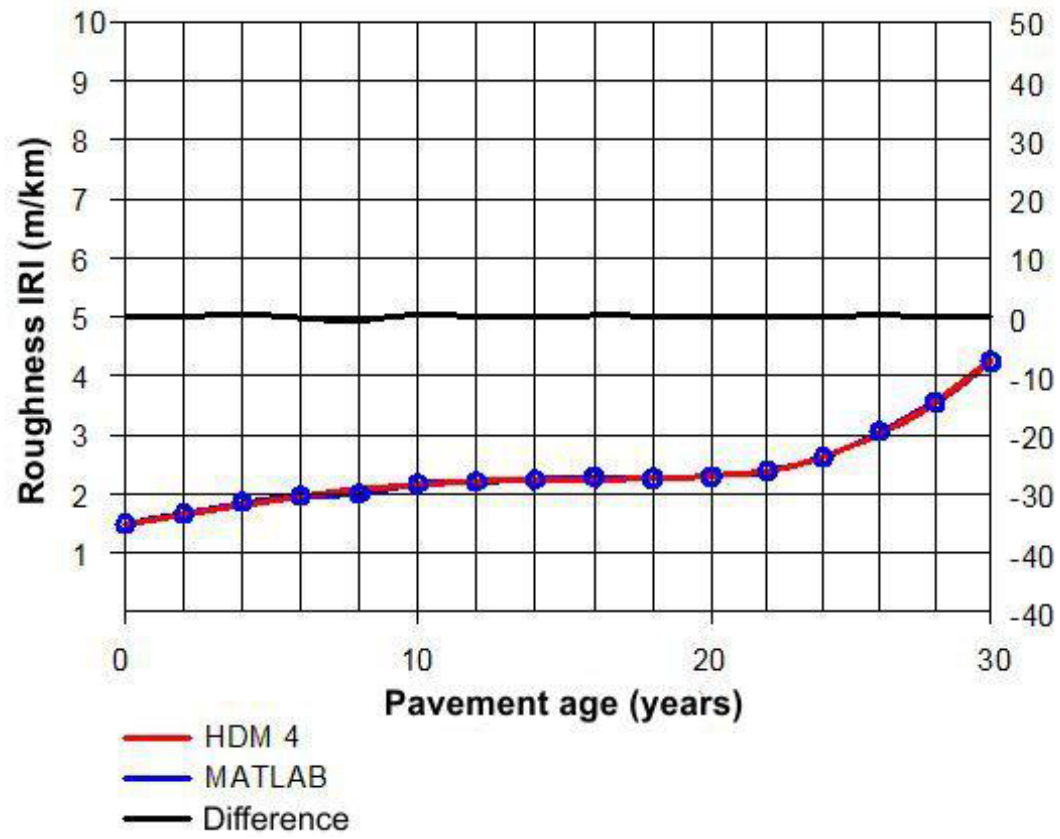

Fig. 3.Validation of the roughness model in MATLAB.

\section{Validation of the results of the forecasts in HDM with the results obtained by field research}

The comparison of the results of the measures wit those obtained by forecasting is necessary to establish the validity of the models for the obtained calibration coefficients. Simply said, validation answers the question of whether the pavement damage models can be, with the sufficient security, used upon the forecasting of the condition on the pavement of the Macedonian highways. Thereby the data from the measures in the last year of the research and the data of the forecasts referring to the same year were used.

The validation was performed by linear regression. The regression equation has the following form:

$$
Y=\frac{a x+b}{1}
$$

Where:X- independent variable (measured data in the research); Y- dependant variable(forecast values of the deterioration in HDM).

\subsection{Validation of the crack initiation model}

The results of the linear regression are given on the following Table 3 .

What can be noted from Table 3 above is that the free member of the regression (Intercept)is approximately 0 , and the coefficient a(X Variable 1)is approximately 1.

The statistic value of $\mathrm{P}=0.2228$, is within the confidence interval (within the limits ofLower $95 \%$ and Upper 95\%), whereas the determination coefficient $\mathrm{R}^{2}$ is approximately 1 (Adjusted R Square=0.937). 
Table3. Results of the statistic validation of the crack initiation model in HDM-4.

\begin{tabular}{|c|c|c|c|c|c|c|c|c|}
\hline \multicolumn{3}{|c|}{ Regression Statistics } & & & & & & \\
\hline \multicolumn{2}{|c|}{ Multiple R } & 0.968266074 & & & & & & \\
\hline \multicolumn{2}{|l|}{ R Square } & 0.937539191 & & & & & & \\
\hline \multicolumn{2}{|c|}{ Adjusted R Square } & 0.937058723 & & & & & & \\
\hline \multicolumn{2}{|c|}{ Standard Error } & 0.796784748 & & & & & & \\
\hline \multicolumn{2}{|c|}{ Observations } & 132 & & & & & & \\
\hline & & df & \multicolumn{2}{|c|}{ SS } & MS & $\mathbf{F}$ & \multicolumn{2}{|c|}{ Significance F } \\
\hline \multicolumn{2}{|l|}{ Regression } & 1 & \multicolumn{2}{|c|}{1238.817126} & 1238.817 & 1951.305 & \multicolumn{2}{|c|}{$3.73606 \mathrm{E}-80$} \\
\hline \multicolumn{2}{|l|}{ Residual } & 130 & \multicolumn{2}{|c|}{82.53257143} & 0.634866 & & & \\
\hline \multirow[t]{2}{*}{ Total } & \multirow[b]{2}{*}{$\begin{array}{c}\begin{array}{c}\text { Coefficie } \\
\text { nts }\end{array} \\
\end{array}$} & 131 & \multicolumn{2}{|c|}{1321.349697} & & & & \\
\hline & & $\begin{array}{c}\text { Standard } \\
\text { Error }\end{array}$ & t Stat & $\begin{array}{c}P- \\
\text { value }\end{array}$ & $\begin{array}{c}\text { Lower } \\
95 \%\end{array}$ & $\begin{array}{c}\text { Upper } \\
95 \%\end{array}$ & $\begin{array}{l}\text { Lower } \\
95.0 \% \\
\end{array}$ & $\begin{array}{l}\text { Upper } \\
95.0 \% \\
\end{array}$ \\
\hline Intercept & 0.106 & 0.0873 & 1.2249 & 0.2228 & $\begin{array}{c}- \\
0.0658\end{array}$ & 0.2796 & -0.0658 & 0.2796 \\
\hline $\begin{array}{l}\mathrm{X} \\
\text { Variable1 }\end{array}$ & 0.977 & 0.02213 & $\begin{array}{c}44.173 \\
6\end{array}$ & $\begin{array}{l}3.74 \mathrm{E}- \\
80\end{array}$ & 0.9337 & 1.0213 & 0.9337 & 1.0213 \\
\hline
\end{tabular}

Therefore, it can be concluded that pursuant toall important statistic parameters, the HDM-4 model of crack initiation is valid and can be used for forecasting of the condition of the pavement on the Macedonian highways.

\subsection{Rutting model validation}

Table4.Results of the statistic validation on the rutting model in HDM-4.

\begin{tabular}{|c|c|c|c|c|c|c|c|c|c|c|}
\hline \multicolumn{4}{|c|}{ Regression Statistics } & & & & & & & \\
\hline \multicolumn{2}{|c|}{ Multiple R } & \multicolumn{2}{|c|}{0.996946588} & & & & & & & \\
\hline \multicolumn{2}{|l|}{ R Square } & \multicolumn{2}{|c|}{0.9939025} & & & & & & & \\
\hline \multicolumn{2}{|c|}{ Adjusted R Square } & \multicolumn{2}{|c|}{0.993863161} & & & & & & & \\
\hline \multicolumn{2}{|c|}{ Standard Error } & \multicolumn{2}{|c|}{1.360693998} & & & & & & & \\
\hline \multicolumn{2}{|c|}{ Observations } & & 157 & & & & & & & \\
\hline & & & df & \multicolumn{2}{|l|}{ SS } & \multicolumn{2}{|c|}{ MS } & $\mathbf{F}$ & \multicolumn{2}{|c|}{$\begin{array}{c}\text { Significance } \\
\text { F }\end{array}$} \\
\hline \multicolumn{2}{|l|}{ Regression } & & 1 & \multicolumn{2}{|c|}{46778.3187} & \multicolumn{2}{|c|}{46778.319} & $\begin{array}{r}25265.2540 \\
7 \\
\end{array}$ & \multicolumn{2}{|c|}{$1.4343 \mathrm{E}-173$} \\
\hline \multicolumn{2}{|l|}{ Residual } & & 155 & \multicolumn{2}{|c|}{$\begin{array}{r}286.980664 \\
4 \\
\end{array}$} & \multicolumn{2}{|c|}{1.8514882} & & & \\
\hline \multicolumn{2}{|l|}{ Total } & & 156 & \multicolumn{2}{|c|}{$\begin{array}{r}47065.2993 \\
6\end{array}$} & & & & & \\
\hline & \multicolumn{2}{|c|}{$\begin{array}{c}\text { Coefficient } \\
\text { s } \\
\end{array}$} & $\begin{array}{c}\text { Standard } \\
\text { Error }\end{array}$ & t Stat & & -value & $\begin{array}{l}\text { Lower } \\
95 \%\end{array}$ & $\begin{array}{c}\text { Upper } \\
95 \% \\
\end{array}$ & $\begin{array}{l}\text { Lower } \\
95.0 \% \\
\end{array}$ & $\begin{array}{l}\text { Upper } \\
95.0 \% \\
\end{array}$ \\
\hline Intercept & \multicolumn{2}{|c|}{0.2062} & $\begin{array}{l}0.1329 \\
\end{array}$ & 1.5512 & \multicolumn{2}{|c|}{0.1229} & -0.0564 & 0.4688 & -0.0563 & 0.4688 \\
\hline $\begin{array}{l}\mathrm{X} \\
\text { Variable1 } \\
\end{array}$ & \multicolumn{2}{|c|}{0.9808} & 0.0062 & 258.95 & \multicolumn{2}{|c|}{$8.2 \mathrm{E}-173$} & 0.9686 & 0.993 & 0.9686 & 0.993 \\
\hline
\end{tabular}

Pursuant to Table 4, similarly as in the crack initiation model, the following conclusion can be drawn:

- Intercept $=0.2062$ (free member of the regression, approximately equal to 0 )

- $\mathrm{X}$ Variable $1=0.9808$ (member beforeXapproximately equal to 1 ) 
- P-value $=0.1229$ (probability of the free member lies within the confidence interval of Lower 95\% and Upper 95\%)

- Adjusted R Square=0.993863161 (determination coefficient, approximately equal to 1 )

In this case it can also be concluded that in relation to all important statistical parameters, it can be concluded that the model of initiation and development of rutting can be used in forecasting the said rutting initiation and development.

\subsection{Roughness model validation}

The data pursuant to which the rutting model was validated are given in P2.1 to P2.6, Annex no. 2.

Table 5. Results of the statistic validation of the roughness model in HDM-4.

\begin{tabular}{|c|c|c|c|c|c|c|c|c|c|}
\hline \multicolumn{4}{|c|}{ Regression Statistics } & & & & & & \\
\hline \multicolumn{2}{|c|}{ Multiple R } & \multicolumn{2}{|c|}{0.966571822} & & & & & & \\
\hline \multicolumn{2}{|l|}{ R Square } & \multicolumn{2}{|c|}{0.934261088} & & & & & & \\
\hline \multicolumn{2}{|c|}{ Adjusted R Square } & \multicolumn{2}{|c|}{0.933735176} & & & & & & \\
\hline \multicolumn{2}{|c|}{ Standard Error } & \multicolumn{2}{|c|}{0.157067444} & & & & & & \\
\hline \multicolumn{2}{|c|}{ Observations } & \multicolumn{2}{|r|}{127} & & & & & & \\
\hline & & & df & \multicolumn{2}{|c|}{ SS } & MS & $\mathbf{F}$ & \multicolumn{2}{|c|}{ Significance F } \\
\hline \multicolumn{2}{|l|}{ Regression } & & 1 & \multicolumn{2}{|c|}{43.82562} & 43.82562 & 1776.46 & & $9.57 \mathrm{E}-76$ \\
\hline \multicolumn{2}{|l|}{ Residual } & & 125 & \multicolumn{2}{|c|}{3.083773} & 0.02467 & & & \\
\hline \multirow[t]{2}{*}{ Total } & & & 126 & \multicolumn{2}{|c|}{46.9094} & & & & \\
\hline & \multicolumn{2}{|c|}{$\begin{array}{c}\text { Coefficient } \\
\text { s }\end{array}$} & $\begin{array}{l}\begin{array}{l}\text { Standar } \\
\text { d Error }\end{array} \\
\end{array}$ & t Stat & P-value & $\begin{array}{l}\text { Lower } \\
95 \%\end{array}$ & $\begin{array}{l}\text { Upper } \\
95 \%\end{array}$ & $\begin{array}{l}\text { Lower } \\
95.0 \% \\
\end{array}$ & $\begin{array}{l}\text { Upper } \\
\mathbf{9 5 . 0 \%} \\
\end{array}$ \\
\hline Intercept & \multicolumn{2}{|c|}{0.0772} & 0.0459 & 1.6816 & 0.0951 & -0.0136 & 0.168 & -0.0136 & 0.168 \\
\hline $\begin{array}{l}\mathrm{X} \\
\text { Variable1 } \\
\end{array}$ & \multicolumn{2}{|c|}{1.0134} & 0.024 & 42.1481 & $9.57 \mathrm{E}-76$ & 0.9658 & 1.061 & 0.9658 & 1.061 \\
\hline
\end{tabular}

The following can be concluded pursuant to table 9.4:

- Intercept $=0.0951$ (free member of the regression, approximately equal to 0 )

- X Variable 1=1.0134 (member beforeXapproximately equal to 1)

- P-value $=0.0951$ (probability of the free member lies within the confidence interval ofLower 95\% and Upper 95\%)

- Adjusted R Square $=0.933735176$ (determination coefficient, approximately equal to 1 )

Similarly to the previous two models, it can be concluded that, in relation to all the important statistic parameters, the pavement roughness model can be used in forecasting the condition related to that parameter.

\section{Conclusion}

The validations of the pavement deterioration models in HDM 4 means, in fact, evaluation of the success of the performed researches upon the definition of the calibration coefficients. MATLAB was used in this research for comparison of the results of the HDM forecasts.

Any other software, in which the pavement deterioration models can be programmed can also be used. 
The obtained validation results indicate the fact that the deterioration models can be successfully used on highways in Macedonia, with some reserve referring to crack initiation, where the differences between the two softwares are considerable.

The statistic method by linear regression is also an appropriate and reliable validation method.

\section{References}

1. Kabupaten Road Economic Evaluation Model.Draft Reporton Pavement Models (Hoff\&Overgaard, Jakarta, 1994)

2. L.Kannemeyer, A.T.Visser, NationalRoads93,799 (1994)

3. M.T.Pavement, Research Report RC, 2051 (2003)

4. T. Martin, Research Report ARR, 255(1994)

5. A. Mohseni, LTPP DataSamplerandRequestProgram (McLean,Virginia, 1995)

6. W.D.O. Paterson, Proposal of Universal Cracking Indicator for Pavements Transportation (TRB, WashingtonD.C, 1994)

7. S.Ognjenovic, Contribution to the management with the sustainable quality condition of the pavement constructions (Faculty of Civil Engineering, Skopje, 2007)

8. S.Ognjenovic, Calibration of the Pavement Construction Damaging Models (Faculty of Civil Engineering, Skopje, 2014)

9. Z. Radojković, Pavement Management Systems (Gradjevinskaknjiga, Belgrade, 1990)

10. Project on the Regional Roads in Macedonia (BCEOM, Macedonia, 2005) 